Investigating Forest Photosynthetic Response to Elevated CO2 Using UAV-Based Measurements of Solar Induced Fluorescence

\title{
Maseyk, Kadmiel
}

IEEE

2018

Maseyk , K, Atherton , J , Thomas , R , Wood , K, Tausz-Posch , S , MacArthur , A , Porcar-Castell , A \& Tausz , M 2018 , Investigating Forest Photosynthetic Response to Elevated CO2 Using UAV-Based Measurements of Solar Induced Fluorescence . in IGARSS 2018 : 2018 IEEE International Geoscience and Remote Sensing Symposium . IEEE International Symposium on Geoscience and Remote Sensing IGARSS, IEEE , pp. 8830-8833 , 38th IEEE International Geoscience and Remote Sensing Symposium (IGARSS) , Valencia , Spain , 22/07/2018 . https://doi.org/10.1109/IGARSS.2018.8517348

http://hdl.handle.net/10138/310561

https://doi.org/10.1109/IGARSS.2018.8517348

unspecified

acceptedVersion

Downloaded from Helda, University of Helsinki institutional repository.

This is an electronic reprint of the original article.

This reprint may differ from the original in pagination and typographic detail.

Please cite the original version. 


\title{
INVESTIGATING FOREST PHOTOSYNTHETIC RESPONSE TO ELEVATED $\mathrm{CO}_{2}$ USING UAV-BASED MEASUREMENTS OF SOLAR INDUCED FLUORESCENCE
}

\author{
Kadmiel Maseyk ${ }^{1}$, Jon Atherton ${ }^{2}$, Rick Thomas ${ }^{3}$, Kieran Wood ${ }^{4}$, Sabine Tausz-Posch ${ }^{5}$, Alasdair Mac \\ Arthur ${ }^{6}$, Albert Porcar-Castell ${ }^{2}$, Michael Tausz ${ }^{3}$
}

${ }^{1}$ School of Environment, Earth \& Ecosystem Sciences, The Open University; ${ }^{2}$ Optics of Photosynthesis Laboratory, Institute for Atmospheric and Earth System Research/Forest Sciences, University of Helsinki; ${ }^{3}$ School of Geography, Earth \& Environmental Sciences, University of Birmingham; ${ }^{4}$ School of Civil, Aerospace \& Mechanical Engineering, University of Bristol; ${ }^{5}$ School of BioSciences, University of Birmingham; ${ }^{6}$ School of Geosciences, University of Edinburgh,

\begin{abstract}
The response of ecosystems to increasing atmospheric $\mathrm{CO}_{2}$ will have significant, but still uncertain, impacts on the global carbon and water cycles. A lot of information has been gained from Free Air $\mathrm{CO}_{2}$ Enrichment (FACE) experiments, but the response of mature forest ecosystems remains a significant knowledge gap. One of the challenges in FACE studies is obtaining an integrated measure of canopy photosynthesis at the scale of the treatment ring. A new remote sensing approach for measuring photosynthetic activity is based on Solar Induced Fluorescence (SIF), which is emitted by plants during photosynthesis, and is closely linked to the rates and regulation of photosynthesis. We proposed that UAV-based SIF measurements, that enable the spectrometer field of view to be targeted to the treatment ring, provide a unique opportunity for investigating the dynamics of photosynthetic responses to elevated $\mathrm{CO}_{2}$. We have successfully tested this approach in a new FACE site, located in a mature oak forest in the UK. We flew a series of flights across the experiment arrays, collecting a number of spectra. We combined these with ground-based physiological and optical measurements, and see great promise in the use of UAV-based SIF measurements in FACE and other global change experiments.
\end{abstract}

Index Terms - Solar Induced Fluorescence, Piccolo Doppio, global change, UAV, photosynthesis

\section{INTRODUCTION}

The ongoing increase in atmospheric $\mathrm{CO}_{2}$ will have profound implications for the coupled carbon and hydrological cycles, and associated climate feedbacks. The necessity to understand the response of terrestrial ecosystems to elevated $\mathrm{CO}_{2}\left(\mathrm{eCO}_{2}\right)$ led to a series of Free Air $\mathrm{CO}_{2}$ Enrichment (FACE) studies being established at a range of sites around the world in the last couple of decades [1]. FACE studies involve fumigating patches of an ecosystem with $\mathrm{CO}_{2}$ (typically in a ring arrangement), elevating the atmospheric
$\mathrm{CO}_{2}$ concentration to levels expected in coming decades. To date, the majority of these studies have been in crop or young plantation forests, with little information from mature forests. To address this knowledge gap, a new FACE site has recently been established in a $c a$. 130-year-old oak forest in the United Kingdom by the Birmingham Institute of Forest Research (BIFoR). Now into its second treatment season, BIFoR FACE represents one of only two active FACE sites in a mature forest globally.

As $\mathrm{CO}_{2}$ is the substrate for photosynthesis, increases in $\mathrm{CO}_{2}$ may lead to an increase in carbon assimilation by the ecosystem; a decrease in stomatal conductance, and therefore water loss, while maintaining similar assimilation rates; or some combination of both responses. An alteration to the carbon input to the ecosystem will cascade through to affect a suite of ecological, physiological and biogeochemical processes. Therefore, an understanding of the photosynthetic responses to $\mathrm{eCO}_{2}$, from leaf to canopy scales, is central to the prediction of ecosystem function under a $\mathrm{CO}_{2}$-rich future.

One of the key challenges in FACE studies is obtaining integrated canopy-level measures of photosynthetic activity. The scale of FACE study sites (10s of meters) sits between the two main approaches used for studies of photosynthesis: leaf or branch chamber measurements, which provided detailed process information on photosynthesis at the leaflevel; and eddy-covariance measurements, which provide information on the net ecosystem-level exchange of $\mathrm{CO}_{2}$, from which gross photosynthetic fluxes can be derived. Bridging the gap between these two scales involves use of multi-layer canopy models. Where infrastructure or canopy height permits, leaf-level measurements can be obtained at low temporal resolution or spatial resolution, but the size of the treatment rings limits eddy-covariance measurements with a footprint confined to the ring area.

During the process of photosynthesis, a small fraction of the absorbed sunlight is re-emitted as fluorescence from the chlorophyll molecules in the red and near infra-red region. Although this chlorophyll fluorescence (ChlF) represents only a few percent of absorbed light energy, it is intimately 


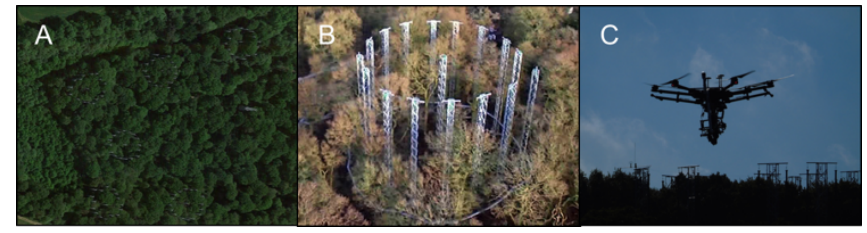

Figure 1. An aerial view of the BIFoR FACE site (A), a closer view of one treatment ring (B) and the UAV flying towards a ring (C).

connected to the photochemical processes and rates of $\mathrm{CO}_{2}$ fixation. Therefore, ChlF emissions provide a signal in the radiance spectrum from vegetation that is directly related to rates and regulation of photosynthesis. While ChlF has been used in studies of photosynthesis for decades at the leaf level, primarily through active manipulation of the fluorescence signal, the fluorescence produced under natural illumination, or Solar Induced Fluorescence (SIF), is emerging as a promising tool for field-measurements of photosynthesis at a range of spatial scales [2]. By exploiting the fact that the $\mathrm{ChlF}$ spectrum overlaps atmospheric $\mathrm{O}_{2}$ absorption lines, estimates of the SIF emissions from vegetation canopies can be obtained using high resolution spectrometers and quantification of the spectral infilling due to ChlF emissions in these regions. This approach has recently been applied at canopy to global scales using tower, airborne and satellite platforms.

We propose that measurements of SIF from a UAV platform provides a unique and unmatched opportunity to measure photosynthetic activity from FACE site treatment arrays, due to the ability to limit the spectrometer field of view to the treatment area. To test this, we conducted an initial campaign at the BIFoR FACE site towards the end of the first treatment season (Fig. 1). We conducted a number of flights across the treatment arrays over the course of a day, and coupled these flights with leaf-level physiological and optical-property measurements. We provide a demonstration of this approach that will be expanded on in subsequent seasons for more detailed studies on forest photosynthetic responses to elevated $\mathrm{CO}_{2}$.

\section{METHODS}

\subsection{Site description}

The BIFoR FACE site is located in a forest of Quercus robur overstory, with a top of the canopy height of $c a .25 \mathrm{~m}$, and a coppiced haze understory in Staffordshire, UK $\left(52^{\circ} 48^{\prime} \mathrm{N}\right.$, $\left.2^{\circ} 18^{\prime} \mathrm{W}\right)$. Elevated $\mathrm{CO}_{2}$ treatment is provided over 3 replicated rings of $30 \mathrm{~m}$ diameter and $25 \mathrm{~m}$ height. In addition, there are 3 control rings (no fumigation) and 3 ghost rings (no infrastructure). $\mathrm{CO}_{2}$ is released from the upwind towers of the rings and regulated to maintain $\mathrm{CO}_{2}$ levels at $550 \mathrm{ppm}$ during the daytime.

\subsection{SIF measurements}

SIF measurements were made using a Piccolo Doppio (Piccolo from here on) dual field of view spectrometer system [3] on 22 September 2017. The Piccolo consists of two spectrometers, a double birfurcated fibre-optic cable connected to upwelling (with cosine diffuser) and downwelling shutter-controlled fore-optics, and a RaspberryPi control board with customised control software. One spectrometer is a high resolution $(0.1 \mathrm{~nm}$ band width, 0.3 nm FWHM, spectral range $640-800 \mathrm{~nm}$ ) Ocean Optics QEPro (Ocean Optics Inc., Florida, USA) covering the ChlF spectrum, and the other an Ocean Optics FLAME-S $(25 \mu \mathrm{m}$ slit, $2 \mathrm{~nm}$ band width, $1.5 \mathrm{~nm}$ FWHM) covering the VIS-NIR range $(350-1000 \mathrm{~nm})$. This setup allows for both upwelling and downwelling irradiance to be collected by both spectrometers, as well as dark current readings, at each measurement cycle. Integration times (shutter opening) was determined manually prior to each flight.

The Piccolo was mounted on a DJI Matrice 600 Pro quadcopter (DJI, Shenzhen, China), using a bespoke gimbal rig to maintain vertical orientation of the fore-optics. Multispectral imagery was also collected with a Parrot Sequoia multispectral camera, and total weight of the system was $c a .15 \mathrm{~kg}$. The measurement routine involved navigating the UAV to the point above the centre of a ring, $40 \mathrm{~m}-50 \mathrm{~m}$ above the top of the canopy, providing a top of canopy FOV of $16-20 \mathrm{~m}$ within the ring. Spectral acquisition was acquired by using a trigger provided from the Pixhawk flight controller system once the UAV was in place. The acquisition routine involved collecting a dark measurement, 15 repeat spectra of both up and downwelling irradiance, and a second dark reading, all from both spectrometers. The full measurement cycle took about 45 seconds.

\subsection{Leaf physiology and optical properties}

On the day before and the day of the flights, branch samples were collected from the top of the canopy by tree climbers. Branch ends with 5-10 leaves on them were cut, taken back to the laboratory facilities on site, and re-cut under water. A number of measurements were made on these samples. Leaf gas exchange and ChlF parameters, including light saturated photosynthetic rates $\left(A_{\text {sat }}\right)$, stomatal conductance $\left(g_{\mathrm{s}}\right)$ and the efficiency of photosystem II ( $\left.\Phi_{\mathrm{PSII}}\right)$ were made using LiCor portable photosynthesis systems (LI6400XT and LI6800, LiCor, Lincoln, Nebraska, USA). Leaf reflectance and ChlF spectra were measured by illuminating the leaves with an LED light with a $600 \mathrm{~nm}$ high-pass filter, and measuring the reflected and emitted light with the FLAME spectrometer. Branches were left over night with dark-adaption clips on them, and the maximum efficiency of photosystem II ( Fv/Fm parameter) measured in the morning with an Opti-Sciences OS5 $p^{+}$pulse modulated portable chlorophyll fluorometer (Opti-Sciences, Hudson, NH, USA) 


\subsection{Calibration}

Radiometric calibration of the system used was made at the NERC Field Spectroscopy Facility, (Edinburgh, UK). A Hoffman integrating sphere radiance source and a FEL irradiance source, both traceable to UK National Physical Laboratory standards, were used. The upwelling (radiance) and downwelling (irradiance) fore optics of the Piccolo were aligned with the respective sources and with the optical path lengths and geometries specified by NPL for their calibration. These calibration measurements are made yearly. At the same time, upwelling and downwelling Piccolo calibration baseline measurement were made using a Piccolo system field calibration validation source. This source, with stabilised power supply and output monitoring picoammeter, can be transported to users' laboratories at periods between the yearly standard calibration and used to assess calibration drift over time and to generate correction coefficients if required. Following the campaign, measurements were made using this field source to link system state back to the primary calibration. In particular, this accounted for a change in the fibre optic cables used between the standard set-up ( $2 \mathrm{~m}$ cables) and the UAV set-up $(0.5 \mathrm{~m})$ cables.

\subsection{System temperature sensitivity}

In addition to the calibration described above, the temperature sensitivity of the Piccolo system was determined using a climate-controlled growth chamber. The Piccolo was placed inside the chamber, and using the $2 \mathrm{~m}$ fibre optic cables connected to the validation light source that was maintained at constant room temperature $\left(19^{\circ} \mathrm{C}\right)$ outside the chamber. The chamber was then set to different temperatures between $6^{\circ} \mathrm{C}$ and $35^{\circ} \mathrm{C}$, and at each temperature the calibration routine of measurements was performed.

\section{RESULTS}

Four successful flights were made over the course of the day, collecting a total of 19 individual spectra sets under mixed sky conditions. Spectra were acquired from each of the treatment and control ring at least once, as well 2 of the ghost rings. The most successful flight collected data from 9 individual rings. Calibrated irradiance and radiance spectra have been calculated from these data (Figure 2). However, low digital numbers in the QEPro upwelling data have prevented us calculating SIF values that we are fully confident in at this stage, and ongoing work involves comparisons with SIF values estimated from the FLAME spectrometer prior to presenting these data.

The gas exchange measurements showed that photosynthetic rates under the elevated $\mathrm{CO}_{2}$ were about $20 \%$ higher than at ambient levels (Figure 3). Rates at a given light-level did not differ between treatment and control trees when measured at the same $\mathrm{CO}_{2}$ concentration. There was large variation in stomatal conductance $\left(g_{\mathrm{s}}\right)$ between samples, but the photosynthetic rate for a given $g_{\mathrm{s}}$ was similar for a given $\mathrm{CO}_{2}$ level (Figure 3). Samples from both treatment and control trees were in good physiological state, as seen in the high and similar Fv/Fm values (Figure 4). The fluorescence spectra are still also to be processed, but initial analysis of the raw data does not indicate strong differences between treatment and control samples.
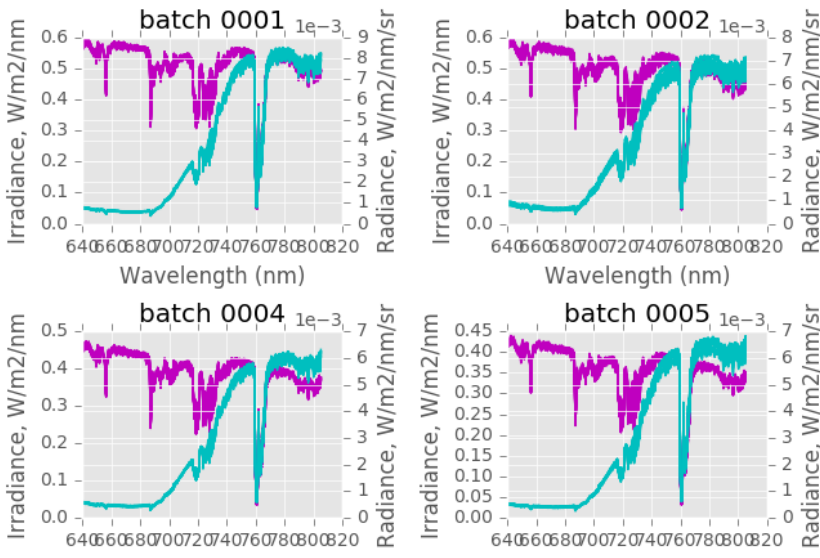

Wavelength $(\mathrm{nm})$

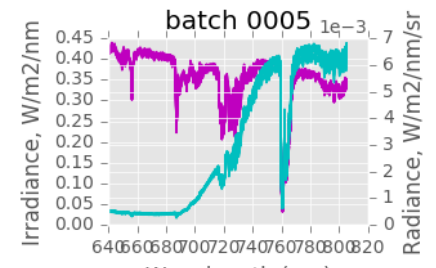

Wavelength $(\mathrm{nm})$

Figure 2 Irradiance (magneta) and radiance (blue) spectra from four separate treatment arrays measured in one flight by the highresolution spectrometer measurements.

There was temperature dependence of the Piccolo system that was directionally opposite between upwelling and downwelling measurements, but in both cases the effect was small (Figure 5). The response was positive with temperature for upwelling, and varied up to $\pm 3 \%$ relative to the response at $20^{\circ} \mathrm{C}$, and negative for downwelling and within $\pm 1 \%$ the response at $20^{\circ} \mathrm{C}$.

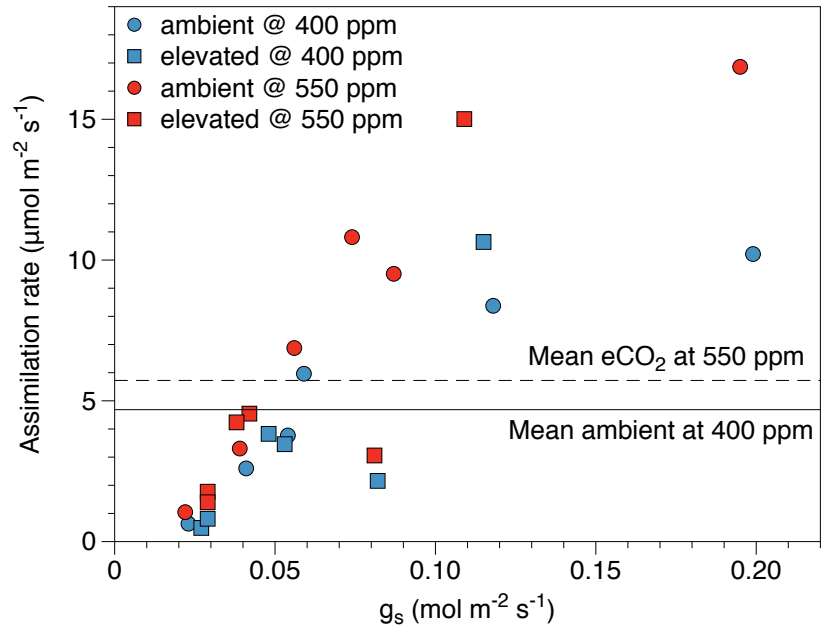

Figure 3. Relationship between stomatal conductance and photosynthesis measured at both ambient and $\mathrm{eCO}_{2}$ concentrations, in samples from both ambient and $\mathrm{eCO}_{2}$ treatments. 


\section{DISCUSSION}

The physiological measurements show that the forest was still largely in a good state, despite being near the end of the season. The $\mathrm{Fv} / \mathrm{Fm}$ values were typical of unstressed plants, and high photosynthetic rates were observed when stomatal conductance was high, indicating good function of the photosynthetic apparatus. A number of samples did however keep stomatal conductance low during the course of the measurements, possibly linked to seasonal down-regulation. Photosynthetic rates at saturating light were, for a given stomatal conductance, higher when measured at the elevated $\mathrm{CO}_{2}$ concentration $(550 \mathrm{ppm})$ than at current ambient concentrations (400 ppm). This increase was similar for both the trees growing at the elevated $\mathrm{CO}_{2}$ treatments and the control sites, indicating that the physiological response to $\mathrm{CO}_{2}$ remains similar, and there is little evidence of acclimation to elevated $\mathrm{CO}_{2}$ in the treatment trees after one year of treatment. The response ratio, or the $\mathrm{eCO}_{2} / \mathrm{ambient}$ ratio of parameters measured at the growth $\mathrm{CO}_{2}$ concentration, was 1.2 for both $A_{\text {sat }}$ and $\Phi_{\text {PSII }}$, which is similar to that recently observed in a mature eucalyptus FACE site [4].

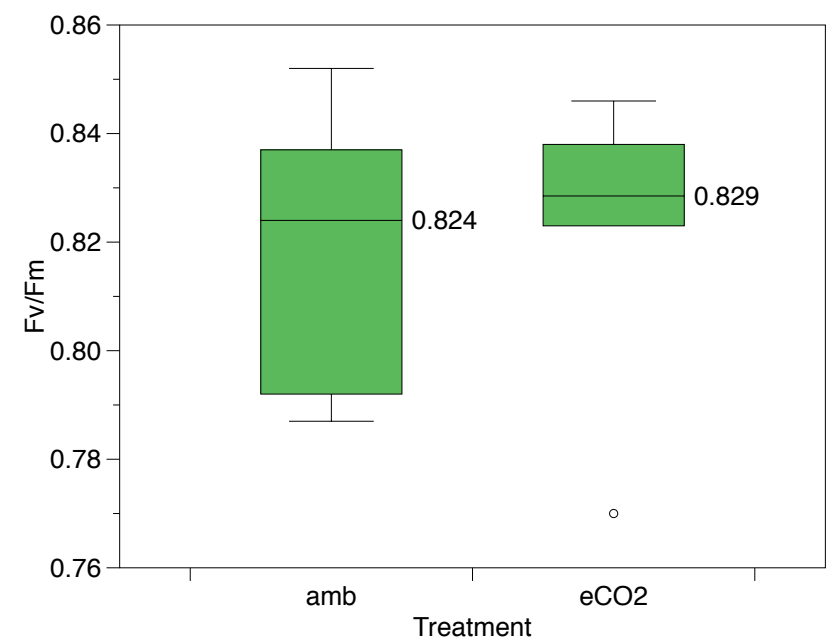

Figure 4. The $\mathrm{Fv} / \mathrm{Fm}$ ratio measured in samples from ambient and elevated $\mathrm{CO}_{2}$ treatments, measured after a night of dark adaptation.

We have explored the feasibility and potential of using UAVbased proximal sensing of SIF to investigate canopy-level photosynthesis across FACE site treatment arrays. We successfully flew the Piccolo Doppio SIF-measurement system across the rings at the BIFoR FACE site, and demonstrated the successful collection of treatment-level radiance and irradiance spectra. Temperature sensitivity tests have shown the Piccolo system does not have a strong dependence in the ambient range, but a small correction may be applied for added precision. Lessons learned include considering taking more time for each ring, in order to run the integration optimization procedure, and measuring less rings per flight, especially under variable sky conditions. On-going work on the calibration and processing of this data will indicate to what extent the differences observed in leaf-level photosynthesis will be apparent in the SIF data. The ability to rapidly obtain an integrated canopy measure of photosynthesis across all treatment arrays from FACE sites, and other large field-manipulation experiments, will provide valuable new insights into the response of ecosystems to elevated $\mathrm{CO}_{2}$ and global change processes.

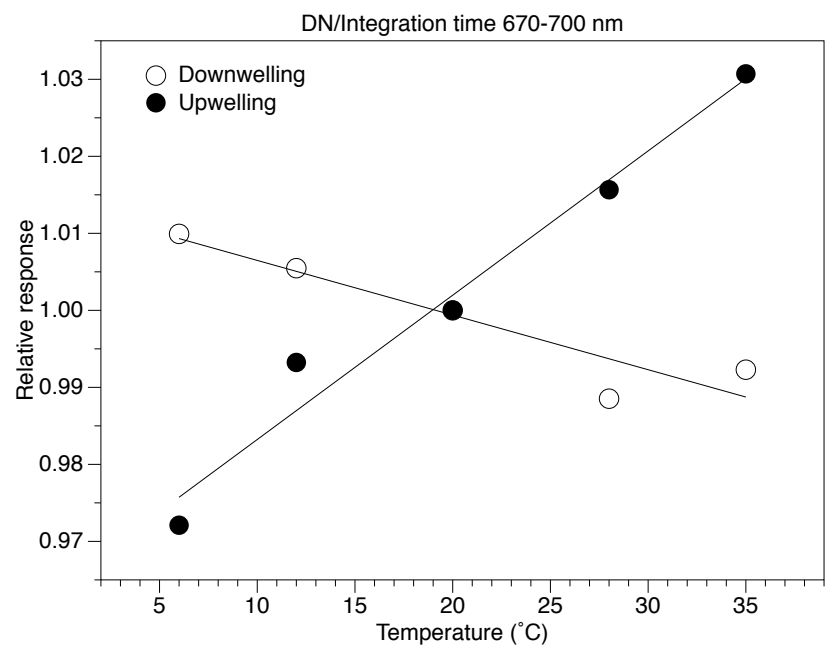

Figure 5 The temperature sensitivity of the QEPro spectrometer in the Piccolo system. Values are the average DN normalised by integration time across the $670-700 \mathrm{~nm}$ region, expressed relative to the value at $20^{\circ} \mathrm{C}$.

\section{REFERENCES}

[1] C. Calfapietra, E. A. Ainsworth, C. Beier, et al., "Challenges in elevated $\mathrm{CO}_{2}$ experiments on forests". Trends in Plant Science, 15(1): p. 5-10, 2010

[2] A. Porcar-Castell, E. Tyystjärvi, J. Atherton, et al., "Linking chlorophyll a uorescence to photosynthesis for remote sensing applications: mechanisms and challenges". Journal of Experimental Botany, 65(15): p. 4065-4095, 2014

[3] A. MacArthur, I. Robinson, M. Rossini, et al. "A dual-field-ofview spectrometer system for reflectance and fluorescence measurements (Piccolo Doppio) and correction of etaloning". In Proceedings of the Fifth International Workshop on Remote Sensing of Vegetation Fluorescence. European Space Agency, 22-24 April 2014, Paris, France.

[4] D. S. Ellsworth, I. C. Anderson, K. Y. Crous, et al., "Elevated $\mathrm{CO}_{2}$ does not increase eucalypt forest productivity on a lowphosphorus soil". Nature Climate Change, 7: p. 279-283, 2017 